\title{
PERANCANGAN ANIMASI TIGA DIMENSI MENGGUNAKAN PERANGKAT LUNAK BLENDER DI CABANG MUHAMMADIYAH KARTASURA
}

\author{
Sukirman \\ Pendidikan Teknik Informatika \\ Fakultas Keguruan dan Ilmu Pendidikan \\ Universitas Muhammadiyah Surakarta \\ Email: sukirman@ums.ac.id
}

\begin{abstract}
ABSTRAK
Animasi merupakan penerapan efek bergerak secara dinamis pada objek statis sehingga terlihat seolah-olah bergerak dalam batas waktu tertentu. Penggunaan animasi untuk tujuan pendidikan dapat menjadikan kualitas pembelajaran lebih baik dan menyenangkan karena dalam animasi dapat memberikan visualisasi yang tidak dapat diwujudkan dalam kejadian nyata. Semakin berkualitas jika guru yang merupakan ujung tombak pendidikan memiliki kemampuan membuat animasi sendiri sehingga materi yang akan disampaikan dapat diterima secara lebih jelas, untuk itulah diadakan kegiatan pengabdian kepada masyarakat dalam bentuk workshop berupa perancangan animasi tiga dimensi menggunakan perangkat lunak Blender yang diperuntukkan bagi guru-guru tingkat SMP/MTs dan SMA/SMK/MA di Pimpinan Cabang Muhammadiyah Kartasura. Dari hasil kuisioner yang diberikan sebelum pelaksanaan kegiatan diperoleh kesimpulan bahwa: (1) Sebagian besar peserta menyukai animasi, namun (2) Tidak terlalu banyak tahu jenis-jenis animasi. (3) Sebagian besar peserta juga memiliki keinginan untuk membuat animasi dengan cerita mereka sendiri, dan (4) setelah mengikuti dan mengetahui cara pembuatan animasi ini mereka memiliki antusias yang tinggi untuk dapat belajar lebih lanjut tentang animasi. Animasi yang dibuat adalah untuk tujuan pendidikan guna meningkatkan kualitas pembelajaran menjadi lebih baik.
\end{abstract}

Kata kunci : animasi, blender, muhammadiyah, kartasura, pendidikan

\begin{abstract}
Animation is applying of moving effects dynamically on static object so it looks like moving within certain time. The use of animation for educational purposes can make the quality of learning be better and fun, because in animation provides visualization that cannot be realized in real life. The more qualified if the teacher who spearhead of education has ability to create their own animation so that the material will be delivered more clearly accepted, for that is held the community services in the form of workshop withthe topic of three-dimensional animation design using Blender software that intended for teachers in level of Junior High Schools / Islamic Junior High Schools and Senior High Schools / Vocational High Schools / Senior High Schools in Muhammadiyah Kartasura Branch. From the results of the questionnaire given before the activities obtained conclusion that: (1) Most participants liked the animation, but (2) Not too much understand about types of animation. (3) Most participants also have a desire to create animations with their own stories, and (4) after following and knowing how to make theanimation, they have a high enthusiasm for learning more
\end{abstract}


p ISSN: 1410-9344, e ISSN: 2549-5631

about animation. The created animation is made for educational purposes to improve learning qualities to be better.

Keywords : animation, blender, muhammadiyah, kartasura, educational

\section{PENDAHULUAN}

Animasi merupakan mekanisme penerapan efek gerak dinamis pada objek statis yang tidak bergerak terhadap ruang dan waktu sehingga menjadikan objek tersebut seolah-olah bergerak (Patil \& Deshpande, 2016). Animasi dapat dibuat dalam format dua dimensi (2D) maupun tiga dimensi (3D). Dalam konteks 2D, merupakan kegiatan yang seolah-olah menghidupkan atau menggerakkan objek/ benda mati menjadi benda hidup dalam koordinat sumbu $\mathrm{x}$ dan y. Objek yang seolah-olah hidup tersebut terjadi karena adanya tampilan gambar yang disusun secara berubah-ubah dalam suatu urutan aturan tertentu. Sementara, animasi 3D berada pada ruang dengan koordinat sumbu $\mathrm{x}$, y, dan z. Dari segi kerealistikan, animasi 3D lebih mendekati nyata dibandingkan animasi 2D. Meskipun begitu, keduanya memiliki keunggulan dan keunikan masingmasing penggemarnya.

Terdapat banyak perangkat lunak (software) yang dapat digunakan untuk membuat animasi 2D maupun $3 \mathrm{D}$, mulai dari yang berbayar hingga benar-benar free atau gratis dan bebas untuk digunakan meskipun untuk kepentingan komersial. Tergantung kebutuhan, apakah memilih untuk menggunakan 2D ataukah 3D. Hanya saja, perangkat lunak 3D umumnnya membutuhkan resource yang lebih besar saat digunakan untuk memproduksi animasi 3D.

Perangkat lunak tidak berbayar dan powerfull yang dapat digunakan untuk membuat pemodelan sekaligus animasi 3D salah satunya adalah Blender, yang dapat diunduh secara gratis di https://www.blender. org. Selain itu, manual dokumentasi dan tutorial juga dapat dilihat di laman tersebut. Banyak produk animasi yang diproduksi menggunakan Blender, salah satu yang terkenal di Indonesia adalah film animasi
"Adit \& Sopo Jarwo" yang ditayangkan di televisi nasional.

Banyak orang menyukai film animasi, karena dapat menghadirkan adegan dan visualisasi yang tidak dapat dilakukan dalam film live-action maupun dalam kejadian nyata. Sebagai contoh untuk tujuan pendidikan, akan dijelaskan mengenai penebangan hutan secara liar yang mengakibatkan banjir bandang, tentu saja hal ini akan sulit untuk diperagakan secara nyata. Dengan adanya animasi, maka penjelasan tersebut akan mudah disampaikan dan menjadi lebih menarik dibanding hanya sekedar cerita dongeng semata. Sehingga, dengan masuknya animasi kedalam dunia pendidikan sebagai media pembelajaran dapat meningkatkan efektifitas dan produktivitas dalam proses belajar mengajar, baik di sekolah maupun di luar sekolah.

Pendidikan merupakan kebutuhan dasar yang diperlukan manusia untuk mengarungi kehidupannya. Dengan pendidikan tersebut, seseorang akan mampu meraih tujuan hidup yang dicita-citakan melalui ilmu yang dimilikinya.Dalam pendidikan, seseorang akan ditempa menjadi pemikir yang dapat hidup bermasyarakat dengan baik. Ilmu pendidikan dapat diraih melalui berbagai madrasah maupun lembaga pendidikan yang ada, misalnya amal usaha bidang pendidikan yang dimiliki oleh organisasi persyarikatan Muhammadiyah.

Amal Usaha Muhammadiyah (AUM) merupakan bentuk kegiatan nyata persyarikatan Muhammadiyah dalam berbagai bidang, antara lain pendidikan, layanan kesehatan, sosial, maupun ekonomi. Khususdalambidang pendidikan, berdasarkan website resmi http://www.muhammadiyah. or.id, organisasi ini memiliki sekitar 247.277 lembaga pendidikan dari tingkat TK/TPQ hingga tingkat Universitas serta pondok 
pesantren. Hal ini menandakan bahwa organisasi Muhammadiyah merupakan salah satu organisasi islam terbesar di Indonesia (Azra et al., 2009) yang memiliki struktur tatanan organisasi dari tingkat pusat hingga tingkat cabang serta ranting yang berada di Desa/Keluarahan.

Secara struktural, Pimpinan Cabang Muhammadiyah (PCM) adalah satu kesatuan yang memiliki aktivitas di tingkat kecamatan dan melaksanakan kebijakan pimpinan yang ada diatasnya mulai dari tingkat Daerah, Wilayah, hingga Pusat (Pimpinan Pusat Muhammadiyah, 2010). Disamping tugas utamanya melaksanakan dakwah, kegiatan lain dari PCM adalah melakukan koordinasi kegiatan AUM yang berada di area cabang tersebut. Satu PCM dapat menaungi beberapa macam amal usaha, antara lain sekolah dasar, sekolah menengah, klinik, rumah sakit panti asuhan, dan masjid yang jumlah dan jenisnya dapat bervariasi dari satu cabang dengan cabang lainnya.

Salah satu Pimpinan Cabang Muhammadiyah yang sudah memiliki aktivitas cukup baik dalam menjalankan AUM adalah Cabang Kartasura, Sukoharjo, Jawa Tengah (Thamrin, H. 2017). Di cabang tersebut memiliki banyak amal usaha, antara lain masjid, rumah sakit, dan sekolah, mulai dari tingkat TK/PAUD hingga SMA/SMK. Akan tetapi, sebagian besar pendidikan yang dijalankan di sekolah-sekolah tersebut masih sangat sedikit yang memanfaatkan animasi sebagai media pembelajaran bagi siswanya. Padahal, animasi memiliki potensi yang sangat bagus dalam meningkatkan kualitas pendidikan.

Untuk mengurangi kelemahan tersebut, maka dilaksanakan pengabdian kepada masyarakat bagi guru-guru di lingkungan pendidikan Muhammadiyah Cabang Kartasura, khususnya dalam hal perancangan animasi 3D. Kegiatan dilaksanakan dalam bentuk workshop di kelas melalui praktik pembuatan animasi secara langsung menggunakan perangkat lunak Blender. Dengan adanya kegiatan ini, diharapkan mampu menambah media pembelajaran animasi ke dalam pendidikan sehingga kualitas pendidikan dapat semakin meningkat.

\section{METODE PELAKSANAAN}

Kegiatan pengabdian kepada masyarakat ini dilaksanakan bagi guru-guru sekolah Muhammadiyah dibawah naungan PCM Kartasura dengan pertimbangan efisiensi penyebaran terhadap akses ilmu yang diperoleh. Kegiatan dilaksanakan dalam bentuk workshop di ruang tertutup, yaitu di laboratorium Sistem Informasi Teknik Informatika Universitas Muhammadiyah Surakarta (UMS). Laboratorium ini dipilih karena fasilitas yang dimiliki cukup memadai untuk penyelenggaraan kegiatan, karena dalam pelaksanaannya membutuhkan perangkat keras berupa komputer dengan spesifikasi Random Access Memory (RAM) minimal 2 GB dan processor 32-bit dual core $2 \mathrm{Ghz}$ untuk menjalankan perangkat lunak Blender 3D. Selain itu, akses ke lokasi juga mudah karena berada di area Cabang Muhammadiyah Kartasura.

Sebelum pelaksanaan kegiatan, peserta diberikan kuisioner untuk diisi guna mengumpulkan data mengenai raw material peserta supaya mengetahui seberapa jauh pemahaman mereka tentang animasi dan antusiasme yang dimiliki. Dengan demikian, ritme dan materi kegiatan dapat disesuaikan sehingga tujuan kegiatan dapat tercapai. Adapun tujuannya adalah agar peserta mampu membuat animasi 3D sederhana menggunakan perangkat lunak Blender.

Kegiatan dilaksanakan dalam bentuk tutorial pengajaran dengan yang diikuti oleh seluruh peserta. Tutor memberikan contoh pembuatan objek 3D untuk dianimasikan dan peserta mengikuti contoh tersebut. Jika terdapat pertanyaan saat pelaksanaan kegiatan peserta diijinkan untuk bertanya langsung saat itu juga supaya dapat mengikuti dengan baik. Sebab tahapan demi tahapan dilaksanakan secara berurutan, apabila tertinggal maka tahap selanjutnya akan sedikit sulit untuk diikuti. 
Tahap terakhir dari pelaksanaan kegiatan adalah evaluasi, digunakan sebagai penilaian terhadap kegiatan yang sudah terlaksana. Sehingga jika suatu saat akan melaksanakan kegiatan serupa, kekurangannya dapat diminimalkan untuk mendapatkan hasil yang lebih baik. Evaluasi dilaksanakan melalui Tanya jawab secara lagsung kepada peserta terkait permasalahan dan kendala-kendala yang ditemui saat kegiatan berlangsung.

\section{HASIL DAN PEMBAHASAN}

Kegiatan workshop dalam acara pengabdian masyarakat ini dilaksanakan pada hari Sabtu, 4 Februari 2017 di Laboratorium Sistem Informasi Teknik Informatika, Fakultas Komunikasi dan Informatika (FKI),
Universitas Muhammadiyah Surakarta (UMS). Pelaksanaan dilakukan dalam ruang tertutup sehingga dapat mengurangi gangguan luar dan lebih fokus pada materi yang disampaikan. Jumlah peserta yang hadir sebanyak 21 guru tingkat SMP/ MTs dan SMA/MA/SMK di area naungan Muhammadiyah Cabang Kartasura.

Sebelum kegiatan workshop dilaksanakan, ada aktivitas mengisi kuisioner yang digunakan untuk mengumpulkan data raw material peserta berkaitan dengan ketertarikan terhadap animasi dan pengetahuan tentang animasi yang sudah pernah mereka temui. Pertanyaan kuisioner tersebut antara lain adalah sebagai berikut:

Tabel 1. Kuisioner pertanyaan

\begin{tabular}{|c|c|c|c|c|c|c|}
\hline No. & Pertanyaan & $\mathbf{0}$ & 1 & 2 & 3 & 4 \\
\hline 1 & Apakah anda menyukai film animasi? & & & & & \\
\hline 2 & Apakah anda tahu jenis animasi yang ada di sekitar anda? & & & & & \\
\hline 3 & $\begin{array}{l}\text { Apakah anda ingin bisa membuat film animasi sendiri dengan } \\
\text { cerita anda sendiri? }\end{array}$ & & & & & \\
\hline 4 & $\begin{array}{l}\text { Tahukah anda bagaimana cara membuat film animasi yang pernah } \\
\text { anda lihat? }\end{array}$ & & & & & \\
\hline 5 & $\begin{array}{l}\text { Setelah mengikuti pelatihan dan tahu cara membuat animasi } \\
\text { sederhana ini, apakah Anda antusias untuk belajar lebih jauh lagi } \\
\text { tentang animasi? }\end{array}$ & & & & & \\
\hline
\end{tabular}

Dalam kuisioner, terdapat 5 pertanyaan yang harus dijawab oleh peserta. Pengisian dilakukan hanya dengan cara memberikan tanda centang pada kolom sebelah kanan pertanyaan. Bobot nilai setiap pertanyaan berkisar antara 0 hingga 4. Semakin besar nilainya, maka bobot penilain juga akan semakin besar, sebaliknya jika angkanya kecil maka bobot penilain juga menjadi rendah.

Sebanyak 19 peserta dari 21 yang hadir mengisi kuisioner, sementara 2 sisanya tidak mengisi karena terlambat mengikuti kegiatan. Dari 19 peserta yang sudah mengisi diperoleh data sebagai berikut.
Tabel 2. Hasil pengisian kuisioner

\begin{tabular}{ccc}
\hline $\begin{array}{c}\text { Pertanyaan } \\
\text { Nomor }\end{array}$ & Nilai Total & Rata-rata \\
\hline 1 & 67 & $88,15 \%$ \\
2 & 27 & $35,52 \%$ \\
3 & 44 & $57,89 \%$ \\
4 & 14 & $18,42 \%$ \\
5 & 55 & $72,37 \%$ \\
\hline
\end{tabular}

Dari hasil pengisian kuisioner tersebut, untuk pertanyaan nomor 1 terkait film animasi, peserta ditanya seberapa jauh peserta menyukai film animasi, dan hasilnya seperti disajikan dalam bentuk pie chart pada gambar 1. 


\section{Apakah menyukai film animasi?}

Suka

Tidak Suka

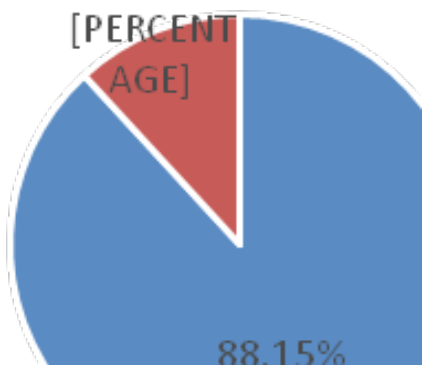

Gambar 1. Hasil pertanyaan pertama

Dari gambar 1 dapat disimpulkan bahwa sebagian besar peserta yang mengikuti kegiatan ini menyukai film animasi, terbukti dari hasil pengisian kuisioner diperoleh bobot penilaian sebesar $88,15 \%$, sementara bobot tidak suka hanya $11,85 \%$.

Pertanyaan kedua berkaitan dengan jenis-jenis animasi yang ada di sekitar peserta, diperoleh ilustrasi pie chart seperti pada gambar 2 .

\section{Tahukah jenis-jenis animasi?}

Tahu

Tidak tahu

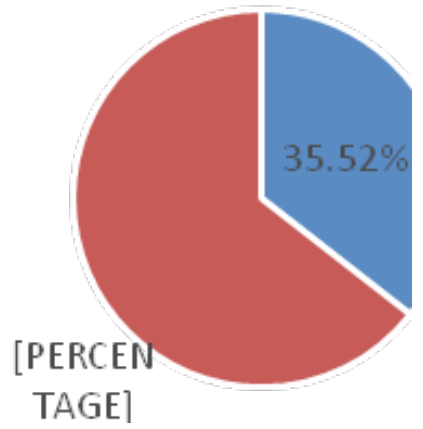

Gambar 2. Pertanyaan jenis animasi

Dari gambar 2 terlihat bahwa ternyata peserta tidak banyak yang mengetahui jenisjenis animasi, yang ditunjukkan dengan bobot nilai sebesar 35,52\%. Ini berarti bahwa mereka belum banyak mengerti tentang jenisjenis animasi dan cenderung menganggap bahwa semua jenis animasi itu sama. Padahal jika dipelajari lebih jauh, ternyata banyak sekali jenis-jenis animasi yang ada, misalnya animasi clay, animasi vektor, animasi objek 3D, dan lain-lain.

Berkaitan dengan keinginan untuk dapat membuat animasi dengan cerita sendiri, didapatkan data seperti yang disajikan pada gambar 3 .

\section{Ingin dapat membuat animasi dengan cerita sendiri?}

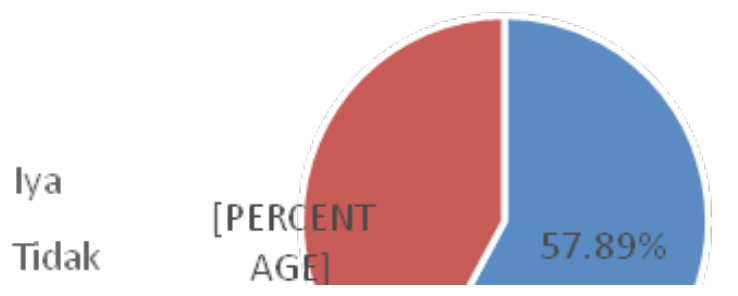

Gambar 3. Hasil pertanyaan ketiga

Meskipun peserta persentasi yang berkeinginan dapat membuat animasi sendiri lebih besar, akan tetapi selisihnya tidak terlalu besar jika dibandingkan dengan peserta yang tidak ingin dapat membuat animasi dengan cerita sendiri, yaitu sebesar $15,78 \%$. Ini berarti bahwa perlu ada pemicu agar motivasi untuk dapat membuat animasi dengan cerita sendiri dapat ditingkatkan.

Dari kuisioner pertanyaan nomor 4 tentang pengetahuan cara membuat animasi, diperoleh data seperti pada gambar 4 .

\section{Tahukah cara membuat animasi?}

Tahu

Tidak tahu

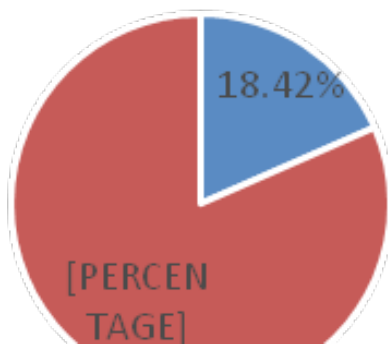

Gambar 4. Hasil pertanyaan keempat

Dari gambar 4 diketahui bahwa hanya $18,42 \%$ saja yang mengetahui cara membuat animasi yang pernah dilihat. Sementara, sebagian besar tidak tahu bagaimana cara membuat animasi yang pernah dilihat. Ini berarti bahwa mereka hanya sebatas menikmati saja tanpa mengetahui bagaimana cara membuat animasi yang dilihatnya.

Pertanyaan terakhir dalam kuisioner adalah tentang tindak lanjut pasca mengikuti dan mengetaui cara membuat animasi melalui 
workshop ini, apakah antusias untuk belajar lebih lanjut atau tidak. Diperoleh data seperti yang disajikan seperti pada gambar 5 .

\section{Antusias belajar animasi lebih lanjut?}

Antusias

Tidak

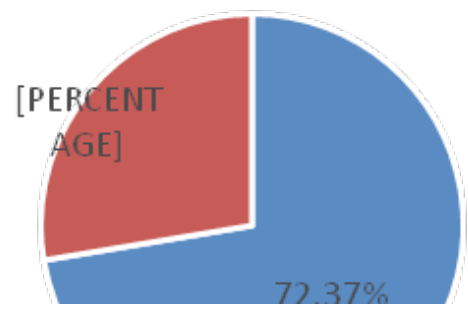

Gambar 5. Kuisioner pertanyaan kelima

Ternyata diperoleh data bahwa sebagian besar peserta antusias untuk belajar lebih lanjut tentang animasi setelah mengikuti pelatihan. Hal ini terlihat dari data yang diperoleh seperti pada gambar 5 menyebutkan sebesar 72,37\%. Sementara, hanya sebagian kecil saja yang tidak antusias.

Antusiasme peserta dalam mengikuti kegiatan tidak hanya terlihat dari kuisioner yang diisi, tetapi dalam pelaksanaan kegiatan juga dapat dilihat, seperti pada gambar 6, Pemateri memberikan penjelasan secara langsung kepada peserta yang mengalami kendala.

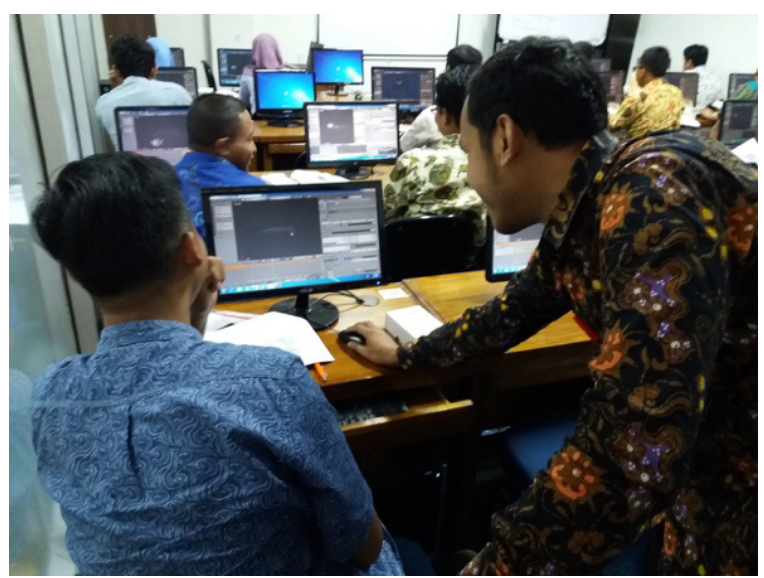

Gambar 6. Pemateri memberikan penjelasan lebih dekat kepada peserta

Pemberian materi dilakukan di sesi awal acara sebelum tutorial pembuatan animasi dilaksanakan, yaitu berupa penyampaian materi tentang animasi secara global hingga khusus tentang animasi komputer beserta perangkat lunak yang digunakan. Sesi awal tersebut terlihat seperti pada gambar 7 .

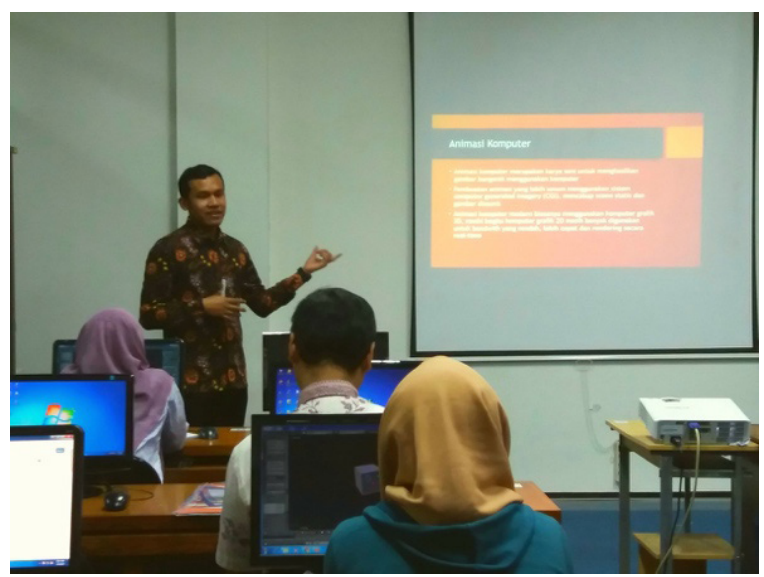

Gambar 7. Penyampaian materi di sesi awal

Di akhir sesi setelah materi workshop selesai, diadakan sesi foto bersama untuk mengabadikan momen kegiatan serta menciptakan rasa kekeluargaan, seperti pada gambar 8 .

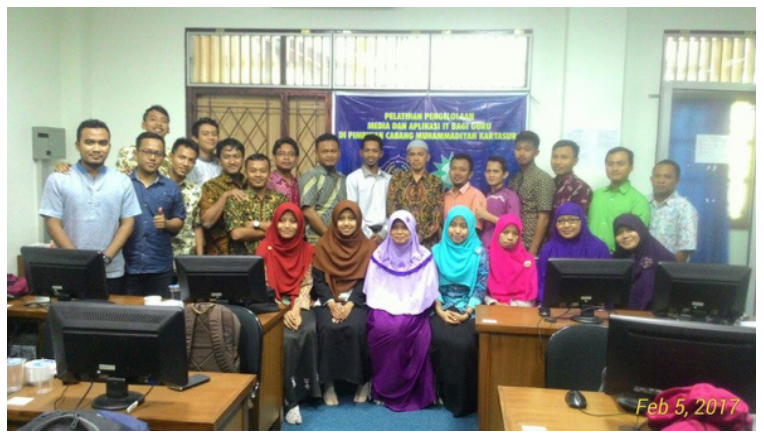

Gambar 8. Sesi foto bersama dengan peserta

Adapun salah satu screenshot hasil workshop berupa pembuatan animasi terlihat seperti pada gambar 9, terlihat sebuah teapot yang dianimasikan bergerak dari layar sebelah kiri menuju sebelah kanan. 


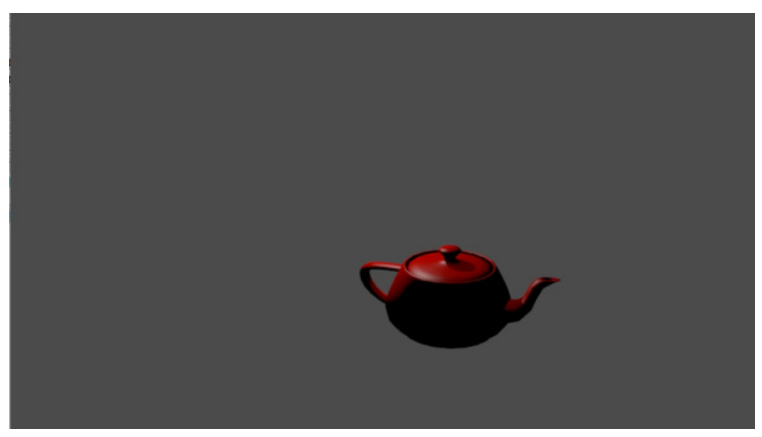

Gambar 9. Animasi teapot

Selanjutnya kegiatan dapat diteruskan di luar pasca kegiatan ini. Meskipun masih terbilang sederhana, tetapi ini merupakan pondasi awal untuk dapat membuat animasi profesional lebih jauh. Dengan demikian, pemanfaatan animasi 3D sebagai media pembelajaran dapat diterapkan di sekolahsekolah sehingga memudahkan siswa dalam belajar demi meningkatnya kualitas pendidikan.

\section{KESIMPULAN}

Dari pelaksanaan kegiatan pengabdian kepada masyarakat yang dilakukan di PCM
Kartasura dengan tema perancangan animasi 3D dengan perangkat lunak Blender ini dapat disimpulkan : (1) Sebagian besar peserta menyukai animasi, namun (2) Tidak terlalu banyak tahu jenis-jenis animasi. (3) Sebagian besar peserta memiliki keinginan untuk membuat animasi dengan cerita mereka sendiri, dan (4) setelah mengikuti dan mengetahui cara pembuatan animasi ini mereka memiliki antusias yang tinggi untuk dapat belajar lebih lanjut tentang animasi. Tentu saja animasi yang dibuat adalah untuk tujuan pendidikan karena seluruh peserta merupakan guru-guru sekolah tingkat SMP/ MTs dan SMA/SMK/MA.

Saran pasca pelaksanaan kegiatan ini adalah, agar peserta dapat menerapkan ilmu yang diperoleh dari pelatihan untuk diterapkan di sekolah masing-masing, baik berupa produk hasil animasi maupun ilmu tentang cara pembuatan animasi menggunakan perangkat lunak Blender 3D.

\section{DAFTAR PUSTAKA}

Azra, A., Sukandar, R., Basya, M. H., Assyaukanie, L., Mu’ti, A., Ghazali, A. R., \& Setiadji, B. (2009). 100 Tahun Muhammadiyah: Civil Society dan Tantangan Gerakan Islam Transnasional. Maarif, 4(2), 1-94.

Patil, G. V., \& Deshpande, S. L. (2016). Distributed rendering system for 3D animations with Blender. In 2016 IEEE International Conference on Advances in Electronics, Communication and Computer Technology (ICAECCT) (pp. 91-98). IEEE. https://doi. org/10.1109/ICAECCT.2016.7942562

Pimpinan Pusat Muhammadiyah. (2010). Anggaran Dasar dan Anggaran Rumah Tangga Muhammadiyah 2005. Yogyakarta: Surya Sarana Grafika

Thamrin, H., \& Albert, S. (2017). Model Multi Situs di Cabang Muhammadiyah Kartasura untuk Efisiensi Pengelolaan Web Berbagai Amal Usaha. WARTA LPPM UMS, 20, No. 1., 40-48. Diakses darihttp://journals.ums.ac.id/index.php/warta/article/view/3438 